\title{
Carbon dioxide not suitable for extinguishment of smouldering silo fires: static electricity may cause silo explosion
}

\section{Hedlund, Frank Huess}

Published in:

Biomass \& Bioenergy

Link to article, DOI:

10.1016/j.biombioe.2017.11.009

Publication date:

2018

Document Version

Early version, also known as pre-print

Link back to DTU Orbit

Citation $(A P A)$ :

Hedlund, F. H. (2018). Carbon dioxide not suitable for extinguishment of smouldering silo fires: static electricity may cause silo explosion. Biomass \& Bioenergy, 108, 113-119. https://doi.org/10.1016/j.biombioe.2017.11.009

\section{General rights}

Copyright and moral rights for the publications made accessible in the public portal are retained by the authors and/or other copyright owners and it is a condition of accessing publications that users recognise and abide by the legal requirements associated with these rights.

- Users may download and print one copy of any publication from the public portal for the purpose of private study or research.

- You may not further distribute the material or use it for any profit-making activity or commercial gain

- You may freely distribute the URL identifying the publication in the public portal 
Share Link - a URL providing 50 days' free access.

Anyone clicking on this link before

$$
\text { January 05, } 2018
$$

https://authors.elsevier.com/a/1W3dr3QkGxkfSd

will be taken directly to the final version the article on ScienceDirect.

No sign up, registration or fees are required

\title{
Carbon dioxide not suitable \\ for extinguishment of \\ smouldering wood pellet \\ fires: static electricity may \\ ignite pyrolysis gasses \\ leading to silo explosion - \\ hazard widely under- \\ appreciated
}

\author{
This is a preprint of \\ Hedlund FH (2017). Carbon dioxide not suitable for extinguishment of smouldering silo \\ fires: static electricity may cause silo explosion. Biomass and Bioenergy (in press). \\ https://doi.org/10.1016/j.biombioe.2017.11.009 \\ Definition of preprint: Author's own write-up of research results and analysis that has not \\ been peer reviewed, nor had any other value added to it by a publisher. \\ The preprint version is different from the accepted manuscript. The peer-review process led \\ to a change to the title, an expansion of section 5.1, a rewrite of the conclusion and a number \\ of minor changes. \\ Allows sharing of Preprints by an author on any website or repository at any time \\ Creative Commons CC BY NC ND
}


Frank Huess HEDLUND

Technical University of Denmark, (DTU/Compute) DK-2800 Kongens Lyngby, Denmark. E-mail fhuhe@dtu.dk ${ }^{a}$

COWI; Parallelvej 2, DK-2800 Kongens Lyngby, Denmark. E-mail: fhhe@,cowi.dk

${ }^{\text {a }}$ corresponding address

\section{Abstract}

Smouldering fires in wood pellet silos are not uncommon. The fires are often difficult to deal with and extinguishment is a lengthy process. Injection of inert gasses to prevent oxygen from reaching the smouldering fire zone and suppress combustion is a new firefighting strategy. This article argues that injection of inert carbon dioxide into the silo headspace is unsafe. Carbon dioxide is generally available as a liquid under high pressure. When discharged, small particles of dry ice are formed. The rapid flow of particles can generate considerable amounts of static electricity, which can act as a source of ignition if ignitable pyrolysis gasses are present. This article discusses a serious wood pellet smouldering fire and silo explosion in Norway in 2010, which took place when firefighters discharged portable CO2 fire extinguishers into the headspace. The attempt to suppress the fire may have ignited pyrolysis gasses. The article examines selected guidelines, standards, popular wood pellet handbooks and other literature and argues that the electrostatic hazard is widely under-appreciated. In the past, major explosions have been attributed to electrostatic ignition of flammable vapours during the release of $\mathrm{CO} 2$ for fire prevention purposes. There is evidence to suggest that those early lessons learned have at least partly passed out of sight.

Keywords:

wood pellets; silo; smoldering fire; explosion; carbon dioxide; static electricity;

Highlights:

- deep-seated fires in wood pellets generate pyrolysis gasses

- flammable pyrolysis gasses can travel and accumulate, e.g. in the silo headspace

- fires cannot be fought with water, novel approaches call for injection of inert gas

- $\quad$ injection of carbon dioxide may generate static electricity, leading to silo explosion

- industry standards and popular pellet handbooks largely silent on the hazard 


\section{Table of Contents}

1 Introduction $\quad 4$

1.1 Smouldering fires in wood pellet silos 4

1.2 Pyrolysis gasses 4

1.3 Water unsuitable for smouldering fires 5

1.4 Alternative firefighting strategies 5

$2 \quad$ Material and methods $\quad 6$

$3 \quad$ Theory $\quad 7$

$\begin{array}{lll}3.1 & \text { Carbon dioxide and static electricity } & 7\end{array}$

$\begin{array}{lll}3.2 & \text { Portable } \mathrm{CO}_{2} \text { extinguishers } & 7\end{array}$

3.3 Past explosions caused by the discharge of portable
$\mathrm{CO}_{2}$ extinguishers

$\begin{array}{lll}3.4 & \text { The Bitburg disaster } & 8\end{array}$

$\begin{array}{lll}3.5 & \text { Summary } & 8\end{array}$

4 The 2010 silo explosion at Hallingdal 9

4.1 The facility's fire history 9

4.2 The silo 9

4.3 Smouldering fire 10

$\begin{array}{lll}4.4 & \text { Explosion } & 10\end{array}$

4.5 Investigation 11

$\begin{array}{lll}4.6 & \text { Source of ignition } & 11\end{array}$

5 Discussion 12

5.1 Clarification of terms: Inerting and purging 12

$\begin{array}{lll}5.2 & \text { German standards } & 13\end{array}$

$\begin{array}{lll}5.3 & \text { NFPA standards } & 14\end{array}$

5.4 Special report on US agricultural silos $\quad 15$

$\begin{array}{lll}5.5 & \text { Swedish contributions } & 15\end{array}$ 
6 Conclusion

$7 \quad$ Conflicts of interest

$8 \quad$ Acknowledgements

20

$9 \quad$ References

21 


\section{Introduction}

\subsection{Smouldering fires in wood pellet silos}

This paper in concerned with unintended ignition of pyrolysis gasses produced by a smouldering fire in a wood pellet storage confinement. Although a smouldering fire may start for several reasons, two causal pathways appear to be common:

- Freshly produced wood pellets may self-heat because energy is liberated from chemical oxidation, moisture absorption or biological processes. Heat loss is largely a surface-based phenomenon and because of the low surface-to-volume ratio of a large pile, any process that generates heat will slowly increase the temperature inside the pile. Pockets may form where the temperature of the contents can rise to the temperature necessary to produce spontaneous ignition. This produces an oxygen deficient smouldering fire deep inside the pile.

- Wood pellets are friable and generate dust and fines when handled in the logistics chain. This dust ignites easily, e.g. from overheated electric motors or conveyor bearings, or from mechanical friction heat between conveyer belts and accumulated pellets, fines and/or dust. Small pieces of smouldering material are difficult to detect and embers may migrate in the band conveyor systems and start smouldering fires in the storage silos.

A small smouldering fire deep inside a storage silo is difficult to detect and may develop into massive storage fires and cause considerable damage to process equipment and property [1].

\subsection{Pyrolysis gasses}

Before developing into an open surface fire, an oxygen deficient smouldering fire generates flammable pyrolysis gasses rich in e.g. toxic and flammable carbon monoxide that can travel and accumulate. Pyrolysis gases may create an ignitable atmosphere in the headspace of the silo. An internal explosion may result when the combustion zone eventually reaches the surface layer or if a source of ignition is present in the headspace. This paper is specifically concerned with potential sources of ignition introduced by firefighters. 


\subsection{Water unsuitable for smouldering fires}

Surface fires in wood pellets can be fought with water, which should be applied gently not to kick up dust and create conditions for a dust explosion. Applying water to a smouldering fire located deep inside a pile however, presents major practical challenges however. In addition, the usage of water has serious drawbacks. Most pellets are hygroscopic and expand when absorbing moisture. When fully saturated with water, compressed pellets may expand about 3.5 times. The wet pellets are sticky and expansion forces may lead to agglomeration and compaction creating a very hard and compact plug.

This creates difficulties during clean-up when the hard material must somehow be broken up for removal, at times requiring a jack hammer. Worse, the expansion may force agglomerations of pellet material to adhere to the walls of the silo, creating hangings or arch formation inside the silo. The sheer force of the expansion may even break the silo walls [1]. Hangings may expose the silo walls to uneven loads for which they are not designed. There are examples of silos that have tipped over due to excessive application of water during firefighting [2].

\subsection{Alternative firefighting strategies}

The challenging nature of fighting fires in wood pellet silo and the drawbacks of using water have led research programmes to explore alternative firefighting strategies, particularly the injection of inert gasses. Inert gasses have the advantages of depleting the oxygen available for combustion, of quenching the pyrolysis and of lowering the risk of ignition of pyrolysis gasses in the headspace. The most commonly available inert gasses in large quantities are nitrogen and carbon dioxide. 


\section{Material and methods}

This article examines a case report of a serious silo explosion in Norway in 2010. The silo, which held freshly made wood pellets, experienced a deep seated smouldering fire. The explosion took place when firefighters attempted to quench the headspace using portable $\mathrm{CO}_{2}$ fire extinguishers. This article argues that electrostatic discharges from the release of carbon dioxide may have ignited pyrolysis gasses in the headspace, resulting in the explosion.

The article examines major standards, guidelines, recent editions of popular pellet handbooks and other literature, versions as per mid-2016. The article presents examples where the hazard is not stated; where the standard, guideline or recommended practice give potentially ill-advised recommendations, and where the absence of a warning may have serious consequences. 


\section{Theory}

\subsection{Carbon dioxide and static electricity}

The ability of carbon dioxide fire to generate static electricity has been known for almost a century. Electrification effects associated with sliding contact between solid $\mathrm{CO}_{2}$ and metal surfaces were reported as early as 1925 . German experiments in the 1950s confirmed that static charging does not occur during the release of purely gaseous $\mathrm{CO}_{2}$, that charging associated with the flow of liquid $\mathrm{CO}_{2}$ is negligible and that strong charging occurs only when solid $\mathrm{CO}_{2}$ particles are present. Butterworth and Dowling [3] provide a good overview of this early work.

\subsection{Portable $\mathrm{CO}_{2}$ extinguishers}

A portable $\mathrm{CO}_{2}$ extinguisher comprises a $\mathrm{CO}_{2}$ storage cylinder, a control valve, a delivery tube and a directional horn. The storage cylinder contains liquid $\mathrm{CO}_{2}$ under its saturated vapour pressure, which at $20^{\circ} \mathrm{C}$ is $5.6 \mathrm{MPa}$ (56 bar). When released, the carbon dioxide undergoes a change of phase from liquid to a mixture of gas and solid. To avoid the risk of electrocution when employed against fires involving electrical equipment, the directional horn must be fabricated from an electrically insulating material. Most of the charge generation is believed to occur within this horn. If the extinguisher and operator are well insulated from ground, for example by an insulating floor or by footwear, the electrostatic potential can rise to $20-30 \mathrm{kV}$ within a few seconds. For some extinguisher designs, potentials up to $50 \mathrm{kV}$ can be attained [3].

If the operator contacts a grounded conductor, he is likely to experience an electrostatic shock. Though the shock in itself is not hazardous, it can be severe enough to deter continuing fire-fighting action and possible ensuing injury is a concern. The shock could lead to a loss of balance or cause the appliance to be dropped, with potentially serious consequences if the operator were in a precarious position such as atop a ladder. 


\subsection{Past explosions caused by the discharge of portable $\mathrm{CO}_{2}$ extinguishers}

Electrostatic discharges from the release of carbon dioxide have sufficient energy to ignite flammable fuel/air mixtures and have been responsible for numerous serious accidents. In New York Harbour in 1966, an attempt to inert damaged tanks of the marine tanker vessel Alva Cape with a carbon dioxide extinguisher, caused naphtha vapours to explode, killing four men and injuring seven [4]. In another case, two firefighters were fatally injured in an explosion, which occurred while they used a portable $\mathrm{CO}_{2}$ extinguisher to inert a tanker truck [5].

\subsection{The Bitburg disaster}

Ignition can take place even if carbon dioxide is released into steel pipework that runs underground for considerable length. A disastrous explosion took place in a JP-4 aviation fuel underground tank at a US Air Force fuel depot near Bitburg, Germany, in 1954, killing 37 people [6].

Various acceptance tests were being made on the newly constructed underground tank and its novel carbon dioxide fire extinguishing system, the first of its kind in Germany. Present were French and German officials, technicians and contractors. The roof of the underground tank was capped with iron reinforced concrete and covered with a layer of soil. Most if not all of the victims were standing on the top of the tank during a controlled activation of the thermal sensing devices that would trigger $\mathrm{CO}_{2}$ cylinders to discharge gas into the tank's headspace.

The $\mathrm{CO}_{2}$ cylinders were located in a half-buried concrete supply house located about $75 \mathrm{~m}$ from the tank and connected to the tank by a 4-inch steel pipeline which branched into two 3" pipelines that followed the circumference of the tank and terminated in four equally distanced discharge outlets . The $\mathrm{CO}_{2}$ pipeline was buried in the ground for its entire length and the discharge outlets were installed flush with the interior tank wall surface and welded to the main steel tank. Although presumably effectively grounded, this piping arrangement conveyed electrostatically charged carbon dioxide.

One minute after the $\mathrm{CO}_{2}$ discharge commenced, a massive explosion disintegrated the tank. The blast blew victims through the air with such force that their bodies were found between the tank and the supply house. The official investigation [6] did not identify carbon dioxide as the source of ignition; its ability to generate static electricity was only realized later [7].

\subsection{Summary}

Back in 1977, Leonard and Clark [5] succinctly summarized the knowledge available at the time, concluding that $\mathrm{CO}_{2}$ fire extinguishers are perfectly satisfactory when used for their intended purpose, i.e., extinguishing a fire, but they should never be used to inert atmospheres containing flammable fuel/air mixtures. 


\section{The 2010 silo explosion at Hallingdal}

\subsection{The facility's fire history}

Hallingdal trepellets is a wood pellet manufacturer is located in $\AA 1$ Municipality, Norway, about $200 \mathrm{~km} \mathrm{NW}$ of Oslo. Raw materials are pinewood and spruce, about 50/50. The facility started production early in 2007.

On April 23, 2007, there was a serious fire, which started in a covered pit with approximately $200 \mathrm{~m}^{3}$ of dry (humidity $8 \%$ ) wood chips in bulk. The chips were still warm from the drying process. An adjacent pit held wet wood chips, humidity about $50 \%$. A wooden wall separated the two pits. The incident started as a minor smouldering fire. Firefighters attempted to localize and contain the fire using various means such as infrared imagery, $\mathrm{CO}_{2}$ extinguishers, fire hoses and steam lances, but the efforts were largely ineffective. Suddenly, the fire intensified, and over a time span of less than 10 minutes, developed into a blaze that spread rapidly to the production building. The fire rendered the facility a complete loss.

The facility was rebuilt. To avoid repeat fire contagion the dried wood chips were kept in a silo and the quantity stored was reduced. In addition, a new concrete wall separated the wood chips area from the production building. The following year, on July 5, 2008, there was a new fire in the wood chips area. This time the damage was limited thanks to the fire safety improvements.

On July 5,2010 , the facility saw a third fire, this time in a $7,742 \mathrm{~m}^{3}$ silo for final product that had been completed the year before. Shortly after midnight, firefighters were called to a smouldering fire in the silo. Eventually, the silo exploded while firefighters attempted to quench the fire with inert carbon dioxide.

\subsection{The silo}

The silo diameter was $24 \mathrm{~m}$ and the circular shell wall was $15 \mathrm{~m}$ tall. The apex of the cone roof was at $21 \mathrm{~m}$. A band conveyor system terminating below the apex dumped freshly produced pellets into a pile below. To draw pellets, sliding doors in the floor could open and dump pellets onto a conveyor band. These doors were closed at the time of the fire. Temperature sensors hung on 
wires that run from the roof to the floor monitor the temperature inside the pellet pile.

To enhance natural ventilation of the headspace, there was a $3 \mathrm{~cm}$ air gap between the silo shell and roof. The total area of the airgap was about $2 \mathrm{~m}^{2}$. The roof was made of thin metal sheets joined to the supporting frame with metal bolts and plastic nuts. The total weight of the roof construction was about $27 \mathrm{t}$. Because plastic nuts were used, the roof construction was believed to be weak and able to serve as overpressure relief in case of an internal explosion [8].

\subsection{Smouldering fire}

Shortly after midnight on July 5, 2010, at 0043 hours, the fire and rescue services were called to the facility. Sensors in the pellet pile showed rising temperatures. The silo was slightly less than 50 percent full, containing an estimated $3,500 \mathrm{~m}^{3}$ of wood pellets. The on-scene-commander arrived at 0130 hours. He soon decided to request a shipment of nitrogen from Yara, a large producer of industrial gasses located in Porsgrunn some $320 \mathrm{~km}$ away. At 0141 hours, the pile temperature had increased to $60^{\circ} \mathrm{C}$ and an alarm came in from the silo's fixed CO detector. At 0242 hours, infrared imagery was able to detect an increased temperature of the silo's outer shell, the pile temperature stayed at about $60{ }^{\circ} \mathrm{C}$. Smoke was now visible above the roof area. Fire fighters received notice that a Yara nitrogen tanker truck was expected to arrive at noon.

$\mathrm{CO}_{2}$ bottles from nearby power stations were mobilized and arrived at 0635 hours. Only 22 bottles were available, about $220 \mathrm{~m}^{3}$ of $\mathrm{CO}_{2}$ gas, just 5 percent of the headspace volume. A revised estimate pushed the arrival of the nitrogen tanker truck to mid-afternoon, at the earliest.

Although the effect of $\mathrm{CO}_{2}$ injection was expected to be limited because of the modest quantities available, a $\mathrm{CO}_{2}$ attack was decided, in the hope that it at least might attenuate the fire until nitrogen supplies arrived. $\mathrm{CO}_{2}$ would be injected manually from a fixed platform located next to a roof inspection hatch. A crane hoisted a basket with the bottles onto the platform and two firefighters with breathing apparatus climbed the silo's exterior ladder to manually discharge the $\mathrm{CO}_{2}$ through the inspection hatch.

\subsection{Explosion}

At 0845 hours, when discharging the fifth $\mathrm{CO}_{2}$ cylinder, the silo exploded. The force of the explosion lifted the $27 \mathrm{t}$ roof upwards and flames of burning gasses shot out of the hatch opening and horizontally from the circumferential edge of the roof. Although the roof is believed to have lifted about $0.5-1 \mathrm{~m}$, it reseated without collapsing. There was no structural damage to the platform and the firefighters were able to descend the exterior ladder to ground level.

The firefighters suffered burn injuries to the ear, back and hand. Luckily, their full personal protective equipment offered excellent protection. There was 
evident heat blister damage to a helmet and to a facial mask. The hood and jacket saw minor burn-through damage. One firefighter suffered burns to his hand because he had taken off one of his bulky gloves in order to operate the valve on the $\mathrm{CO}_{2}$ cylinder.

After the explosion, the silo was considered a complete loss and an excavator was called in to tear a hole in the silo wall in order to empty the silo and extinguish the burning material outside. When the silo was torn open, a large surface fire was visible inside the silo.

\subsection{Investigation}

Based on readings from the temperature sensors hung on wires inside the silo, the smouldering fire was believed to have started near the centre of the pellet pile. Pellets had not been drawn from the silo for two weeks and it was speculated that self-heating of pellets deep inside the undisturbed pile could have started an oxygen deficient smouldering fire. Pyrolysis gasses would then accumulate in the silo's headspace.

The investigation identified the likely source of ignition to be a combustion zone break-through to the surface layer of the pellet pile. The wind was blowing steady at $8-10 \mathrm{~m} / \mathrm{s}$ and the investigation report argued that sufficient turbulent entry of air through the $3 \mathrm{~cm}$ airgap between the shell and roof could have formed an ignitable pyrolysis gas mixture under the roof. In addition, that additional air entered the headspace through the open hatch when $\mathrm{CO}_{2}$ was injected due to backdraft and wind.

The investigation did not identify electrostatic effects due to injection of carbon dioxide as a possible source of ignition. The national independent highly qualified senior fire investigator later stated that this mechanism was unknown to him.

\subsection{Source of ignition}

Ignition may have been caused by a sudden combustion zone break-through to the surface layer or by static electricity. There is no empirical basis for this article to enter a discussion on the likelihood of either mechanism. From an industrial accident prevention perspective, what matters most is the lack of awareness of the hazard of electrostatic effects amongst emergency responders and accident investigators. 


\section{Discussion}

\subsection{Clarification of terms: Inerting and purging}

Terminology is important and it is useful to clarify precisely what is meant by inerting and purging.

Where an ignitable mixture is contained, such as in a processing vessel, the atmosphere can be made oxygen deficient by introducing enough inert gas to make the mixture non-ignitable. This technique is known as inerting in NFPA 69 [9] and NFPA 77 [10]. The key characteristic is that the mixture of flammable gas and air is in the ignitable range before an inert gas is introduced.

A different situation exists during start-up of process equipment. Before a flammable gas is introduced into a system containing air, it is often recommended that the air in the system be diluted by a nonreactive (inert) gas such as nitrogen, carbon dioxide, or argon to low concentrations so that when flammable gas is introduced, an ignitable mixture cannot form within the system. In the terminology commonly used in the petrochemical industry, this practice is known as "purging into service" [11].

A similar situation arises during shut-down. If a system that contains a flammable gas is to be taken out of service, the gas can be diluted by an inert gas to low concentration, so that when air is introduced, an ignitable mixture is not created within the system. This practice is known as "purging out of service" [11].

While the two purging practices are similar in principle, it is useful to have two distinct concepts because purging out of service requires much larger quantities of inert gas than purging into service. Carbon dioxide may be a suitable inert gas because both purging practices ensure that an ignitable mixture never forms in the system. Hence, in theory, the introduction of a possible source of ignition due to static discharges is of no concern.

Unfortunately, because an inert gas is used, both purging practices may loosely be referred to simply as "inerting". But purging should not be confused with inerting where an ignitable mixture of flammable gas and air is made safe by adding an inert gas. Carbon dioxide is unsuitable for this purpose. 


\subsection{German standards}

Much of the early knowledge and insights regarding the ability of $\mathrm{CO}_{2}$ to create electrostatic discharges is based on work carried out in Germany, in particular insights gained after the disastrous Bitburg explosion in that country. It is therefore noteworthy, that the hazard has no prominent place in German rules and guidelines.

In Germany, the dangerous substances regulations are known as the Technische Regeln für Gefahrstoffe, TRGS (Technical rules for dangerous substances). The explosive atmospheres regulations are known as "Technische Regeln für Betriebssicherheit", TRBS (Technical Rules for Operating Safety). Some of them overlap. The relevant regulations are TRBS 2152, which comes in four parts [12-15]. Both the general section (part 1) [12] and the detailed technical requirements for preventing or mitigating a hazardous explosive atmosphere (part 2) [13] are silent on the electrostatic discharge hazard.

It is true, that part two deals only with purging in and out of service, in German terminology referred to as "partial inerting" and "total inerting" respectively, for which static discharges in principle are of no concern. Still, a warning about electrostatic discharges might be particularly relevant, for instance, in section 2.3.4, which deals with vessels in vacuum service, for which the safety system can be so designed that detection of an operational upset with air ingress will trigger an automated inerting response. The absence of a warning is noteworthy because the standard lists other types of situations where carbon dioxide (and nitrogen) are unsuitable inerting agents, e.g., that fine dusts of certain light metals may undergo chemical reaction with these gasses.

Part three [14] of TRBS 2152 does make passing reference on page 29 to another standard, TRBS 2153 [16], which deals with static electricity, but there is no specific mention that the inert gas carbon dioxide itself could be a source of static electricity. The TRBS 2153 standard on electrostatics clearly identifies the static hazard on pages $64-65$ out of 128 . It states that processes that may produce considerable static discharge include: "pneumatic transport of solids, a release of pressurized gas with solids, the discharge of liquid carbon dioxide, industrial vacuum cleaners and spray painting operations" [16] (emphasis added).

The TRBS 2153 standard also covers the situation when an ignitable mixture of flammable gas and air is to be made safe by adding an inert gas quite extensively, which is referred to simply as "inerting", similar to the terminology of NFPA 69 and NFPA 77. The standard cautions that the discharge of a fire extinguishment agent, which could produce static discharges, should never be carried out for test purposes, when a potentially explosive atmosphere exists. The standard specifically states that $\mathrm{CO}_{2}$ and wet steam (steam with droplets of water) are unsuitable inerting agents for this purpose [16]. This is the closest reference to the lessons learned from the Bitburg disaster.

In conclusion, is it probably fair to assume that safety-conscious readers with a prior concern or expectation that $\mathrm{CO}_{2}$ is able to create hazardous electrostatic 
discharges will consult the TRBS 2153 standard on static electricity [16] and see their prior expectation confirmed. Safety-conscious but unsuspecting readers, however, are likely to consult the TBRS 2152 standard on flammable atmospheres only. A meticulous examination of the four documents that comprise this standard will provide no clue as to the electrostatic hazard.

It is true that information on the electrostatic hazard does exist. A German fire safety professional kindly informed that the European Industrial Gases Association (EIGA) covered the issue in a safety newsletter [17], which is also available in English [18]. This article argues however, that there is considerable evidence to suggest that the hazard is not widely appreciated. For instance an article in a German firefighter magazine [19] discusses two cases of fighting smouldering silo fires using $\mathrm{CO}_{2}$, evidently oblivious of the electrostatic hazard.

\subsection{NFPA standards}

NFPA standards mirror German ones, confirming the electrostatic hazard of carbon dioxide to those readers who consult a standard on static electricity because they already suspect the gas to have these properties, but are otherwise mostly silent on the issue. NFPA 77 on static electricity clearly states that carbon dioxide from high-pressure cylinders or fire extinguishers should never be used to inert a container or vessel [10] (emphasis added).

NFPA 69 [9] on explosion prevention systems does neither mention electrostatic effects nor refer to NFPA 77 although the standard lists the following purge gas sources as acceptable: commercially available inert gas, such as nitrogen, carbon dioxide, argon, or helium, supplied from high-pressure tanks or cylinders. The standard's use of the terms purging and inerting is not entirely unambiguous.

NFPA 12 [20] on carbon dioxide extinguishing systems provides potentially ambiguous advice on the electrostatic hazard. Annex A states that the discharge of liquid carbon dioxide is known to produce electrostatic charges that, under certain conditions, could create a spark and duly refers to NFPA 77. The standard also specifies, that "carbon dioxide fire-extinguishing systems protecting areas where explosive atmospheres could exist shall utilize metal nozzles, and the entire system shall be grounded" [20, Sec. 4.2.1] (emphasis added). The first issue of concern is if the reader realizes that an explosive atmospheres can exist not only when flammable liquids give off vapours but also when pyrolysis gasses have accumulated. The second issue of concern is if effective grounding is sufficient to prevent hazardous electrostatic discharges - the Bitburg accident would appear to contraindicate this. The third and perhaps most important issue of concern is the standard's advice on the application of $\mathrm{CO}_{2}$ to "deep-seated fires involving solids subject to smoldering" [20, Sec 5.2.3]. This is precisely the situation where pyrolysis gasses may have accumulated in the headspace to an extent where they are in the ignitable range - but the reader may not have realized this, and the standard does not identify the potential presence of flammable gasses. The nub of the issue may well be 
lack of clarity in the meaning of the terms "fire" and "extinguishment", which are not defined in the standard's terminology section. The application of $\mathrm{CO}_{2}$ is excellent for extinguishing a fire with flames, but unsuitable for quenching a deep seated smouldering fire without flame.

Annex A of the NFPA 850 [21] covers spontaneous heating, hotspot formation and fire in coal silos Firefighting in coal silos is a long and difficult activity, the standard says, but carbon dioxide and nitrogen have been used successfully as gaseous inerting systems. The standard specifically states that carbon dioxide vapour has proven to be effective in quickly establishing an inert atmosphere in the space above the coal, which prevents the creation of an explosive atmosphere there. Carbon dioxide has the advantage over nitrogen of being denser than air, the standard says. Because nitrogen has a density similar to air it must be applied at numerous injection points around the silo to ensure that it displaces available oxygen. Compared to carbon dioxide, the standard says, nitrogen requires more injection equipment and a larger quantity of agent.

It is true that injection of carbon dioxide can prevent the creation of an explosive atmosphere in the silo headspace. This article argues however, that the procedure is unsafe because plant personnel or firefighters usually have limited means to determine if pyrolysis gasses present in the headspace are already in the ignitable range when the injection begins. The standard is silent on the electrostatic hazards of carbon dioxide.

\subsection{Special report on US agricultural silos}

Fires and explosions in agricultural silos have been responsible for the deaths and injuries of firefighters and civilians and have led to large loss of property. In response to a number of agricultural silo emergencies, the United States Fire Administration issued a Special Report in 1998 [22] in order to communicate significant lessons learned.

Spontaneous ignition and smouldering fires in agricultural silos present challenges to firefighters. The report states that extinguishment may be accomplished by injecting nitrogen or carbon dioxide into the silo using special fittings and piping. The report is silent on the electrostatic hazards of carbon dioxide.

\subsection{Swedish contributions}

Sweden is the only country in Scandinavia with a significant domestic pellet production. The domestic pellet market is mature and pellet consumers are diverse, from single-family households, industry, district-heating systems and large Combined Heat and Power (CHP) plants. For many years, Sweden was the largest consumer of wood pellets in the EU and was only in 2012 surpassed by Italy and Denmark [23].

Ambitious and foresighted research programmes have been undertaken by the Swedish National Testing and Research Institute (in Swedish: Sveriges 
Prövnings- och Forskningsinstitut, abbreviated to SP) to address, inter alia, the challenges with wood pellet silo fires. In 2006, the SP reported the results of an experimental study on fire extinguishment in wood pellet silos [24]. The study concluded that extinguishment should be carried out with injection of nitrogen or carbon dioxide, primarily into the bottom of the silo, although injection into the headspace at an early stage could be considered in order to eliminate explosion risks, i.e. inerting. According to the report, the use of carbon dioxide merely presents practical problems because injection lances freeze up - the report is silent on the risk of electrostatic discharges.

The inert gas technique was applied e.g. in 2007, when a pellet silo in Kristinehamn, Sweden, experienced a smouldering fire due to self-ignition [25]. Tanker trucks with nitrogen and carbon dioxide were called to the site. Preparations for injection of nitrogen into the bottom of the silo were repeatedly delayed due to multiple complications when drilling openings in the concreate silo and with the improvised making of custom injection lances. Not to waste time, carbon dioxide was therefore introduced into the silo headspace through a fire hose. The hose froze up and plugged repeatedly. A total of $35 \mathrm{t}$ of carbon dioxide were injected without incident. Evidently, the emergency responders and technical advisors from SP were oblivious to the risk of electrostatic discharges.

In 2011, the novel inert gas approach was communicated widely in Biomass Magazine [26] and Canadian Biomass [27], without mention of the electrostatic hazard. The Swedish experiences have also found way into popular pellet handbooks, e.g. [1] published in 2012, which merely states that attempts to use carbon dioxide without a vaporisation unit have caused many unsuccessful extinguishing operations as the supply hoses/lances /nozzles and the bulk material close to the injection point tend to freeze quickly, blocking further gas injection. An almost verbatim description is provided in an otherwise comprehensive publication on health and safety aspects of solid biomass published in 2013 by the International Energy Agency [28]. The publications are also silent on the risk of electrostatic discharges.

In 2013, the Swedish Civil Contingencies Agency issued a report on silo fires, written in English and clearly intended for an international audience [2]. This report, at last, does advice against the use of $\mathrm{CO}_{2}$ due to risks of static electricity during gas injection. But the report is a sole voice of caution in an abundance of standards, guidelines and literature that appear to be oblivious of the hazard. 


\section{Conclusion}

Policy makers and risk analysis professionals may wish that the state of knowledge is always increasing, that accident prevention knowledge is continuously improving, as if obeying a fundamental law of physics. This case shows that the opposite can occur. That important information on hazards, learned the hard way through investigation of past disastrous explosions, can pass out of sight. This appears to have happened in the fast growing wood pellet sector where difficulties with smouldering fires has led to new techniques for firefighting which employ inert gasses, of which carbon dioxide is one.

With the increase in the quantities of solid biomass handled, this knowledge loss becomes significant. The smouldering fires are difficult to deal with, water is not a suitable extinguishment agent, and firefighters, who are men of action, can become frustrated if having to wait idly for supplies of nitrogen to arrive. If carbon dioxide extinguishers are available it may be tempting to "do something" to retard fire development.

It is true that standards on static electricity, e.g. NFPA 77, do mention the electrostatic hazard of carbon dioxide. Safety conscious readers however, are likely to consult such standards only if they already suspect carbon dioxide to have electrostatic properties. Safety conscious but unsuspecting readers will likely consult standards on flammable atmospheres only, which are silent on the electrostatic hazard. Popular wood pellet handbooks are also silent on the hazard.

NFPA 12 on carbon dioxide extinguishment systems should be more specific on the presence of pyrolysis gasses when extinguishing smouldering fires. The application of $\mathrm{CO}_{2}$ is excellent for extinguishing a fire with flames, but can be unsuitable for quenching a deep seated smouldering fire without flame.

The standards, guidelines and handbooks examined provide little information on the electrostatic hazards of carbon dioxide, supporting a general conclusion that that the hazard appears to be widely under-appreciated, across countries. Important fields of application, such the practice of installing $\mathrm{CO}_{2}$ extinguishment systems in the cargo hold of marine vessels, some carrying wood pellets susceptible to smouldering fires, could not be covered in this work. More research into the subject is needed.

The past decade has seen a major increase in the consumption of wood pellets. The growth has been mirrored in an increase of pellet related accidents 
involving fires, dust explosions and toxic gasses, some of which have been poorly investigated, causes not identified and lessons not learned [29,30]. A small but growing body of literature argues that bioenergy and other lowcarbon energy systems present major accident hazards [31-34]. There are even indications that the number of accidents in the bioenergy sector is growing faster than the energy production [33].

Utmost care should be taken to avoid so-called media- shifting [35], i.e. that the resolution of a problem within one domain, the environmental, creates a new problem in another, the workplace safety domain. 


\section{$7 \quad$ Conflicts of interest}

The author has no conflicts of interest to declare. 


\section{Acknowledgements}

I'm grateful to Dag Botnen, Fire Chief Officer, Hallingdal Fire Service.

Torpomoen, for valuable inputs and helpful discussion on the 2010 fire and explosion event.

This article has been produced as a voluntary effort and did not receive any specific grant from funding agencies in the public, commercial, or not-forprofit sectors. Opinions expressed are those of the author, not his employers' or organizations'. 


\section{$9 \quad$ References}

[1] G. Thek, I. Obernberger, The pellet handbook: the production and thermal utilization of biomass pellets, Routledge, 2012.

[2] H. Persson, Silo Fires - Fire extinguishing and preventive and preparatory measures. Publication: MSB586, Swedish Civil Contingencies Agency (MSB), Karlstad, Sweden, 2013.

[3] G.J. Butterworth, P.D. Dowling, Electrostatic effects with portable CO2 fire extinguishers, J. Electrostat. 11 (1981) 43-55. doi:https://doi.org/10.1016\%2F0304-3886\%2881\%2990075-9.

[4] G. Horne, Report Assesses Alva Cape Blast; Coast Guard Says Proper Supervision Was Lacking, New York Times. March 09 (1967) 77.

[5] J.T. Leonard, R.C. Clark, FF 1977 - Leonard - Ignition of flammable vapors by CO2 fire extinguishers.pdf, J. Fire Flammabl. 8 (1977) 131-134.

[6] W.G. Ritter, Underground JP-4 fuel tank explosion : Bitburg Germany, 34 dead, 2 injured and 3 missing, September 23, 1954, NFPA Fire Loss Bull. 1 (1955) 1-4.

[7] K. Nabert, G. Schön, Folgerungen aus den Untersuchungen über die Ursache der Explosionskatastrophe bei Bitburg (in German) [Conclusions from investigations into the cause of the explosion disaster at Bitburg], Erdöl Und Kohle. 8 (1955) 809-810.

[8] D. Botnen, Hallingdal trepellets 5. juli 2010 (in Norwegian) [Hallingdal wood pellets], Hallingdal Fire Service, Torpomoen, Norway, n.d.

[9] NFPA 69. Standard on Explosion Prevention Systems. 2014 Edition, National Fire Protection Association, Quincy, Massachusetts, USA, 2013.

[10] NFPA 77. Recommended Practice on Static Electricity. 2014 Edition, National Fire Protection Association, Quincy, Massachusetts, USA, 
2013.

[11] NFPA 56. Standard for Fire and Explosion Prevention During Cleaning and Purging of Flammable Gas Piping Systems. 2014 Edition, National Fire Protection Association, Quincy, Massachusetts, USA, 2013.

[12] Technische Regeln für Betriebssicherheit. TRBS 2152 Teil 1 / TRGS 721. Gefährliche explosionsfähige Atmosphäre - Beurteilung der Explosionsgefährdung [Technical rules for workplace safety. Part 1. Dangerous explosive atmospheres - Assessment of expl risk], Bundesanzeiger Nr. 103a vom 2. Juni 2006 [German Federal Register], Köln, Deutschland, 2006.

[13] TRBS 2152 Teil 2 / TRGS 722. Vermeidung oder Einschränkung gefährlicher explosionsfähiger Atmosphäre. Technische Regeln für Betriebssicherheit. Ausgabe: März 2012 [Part 2: Prevention or reduction of explosive atmospheres], Gemeinsame Minist. 22 (2012) $398-410$.

[14] TRBS 2152 Teil 3. Gefährliche explosionsfähige Atmosphäre Vermeidung der Entzündung gefährlicher explosionsfähiger Atmosphäre. [Part 3. Prevention of ignition of explosive atmospheres], Gemeinsame Minist. 77 (2009) 1583.

[15] TRBS 2152 Teil 4. Gefährliche explosionsfähige Atmosphäre Maßnahmen des konstruktiven Explosionsschutzes, welche die Auswirkung einer Explosion auf ein unbedenkliches Maß beschränken. [Part 4. Measures to limit the effects of an explosion], Gemeinsame Minist. 21 (2012) 387.

[16] TRBS 2153. Vermeidung von Zündgefahren infolge elektrostatischer Aufladungen. [Prevention of electrostatic ignition sources.], Gemeinsame Minist. 15/16 (2009) 278.

[17] EIGA, Das Risiko statischer Elektrizität beim Einsatz von CO2 zur Inertisierung, EIGA Saf. Newsletter. NL76/02/D. (2002). http://www.industriegaseverband.de/eiga/eigasafetynews/7602D.pdf (Retrieved Feb 21, 2017).

[18] EIGA, Risk of generating static electricity when using CO2 as an inerting agent / Treatment of cylinders \& containers in scrap yards, EIGA Saf. Newsletter. NL76/02/E (2002). https://www.eiga.eu/fileadmin/docs_pubs/NL_76_02_E.pdf (Retrieved Feb 21, 2017).

[19] A. Weiß, Inertisierung mit Kohlendioxid oder Stickstoff bei Schwelbränden in Silos (in German) [Inerting smouldering fires in 
silos with CO2 or N2], Brand. Feuerwehr-Zeitung. 11 (1981) 390393.

[20] NFPA 12. Standard on Carbon Dioxide Extinguishing Systems. 2015 Edition, National Fire Protection Association, Quincy, Massachusetts, USA, 2014.

[21] NFPA 850: Recommended Practice for Fire Protection for Electric Generating Plants and High Voltage Direct Current Converter Stations. 2015 Edition, National Fire Protection Association, Quincy, Massachusetts, USA, 2014.

[22] A. Clark, J. Kimball, H. Stambaugh, The Hazards Associated with Agricultural Silo Fires (Report 096 of the Major Fires Investigation Project), United States Fire Administration, Federal Emergency Management Agency, Emmitsburg, Maryland, USA, 1998.

[23] B. Flach, S. Lieberz, M. Rondon, B. Williams, C. Teiken, EU Biofuels Annual 2015. (Global Agricultural Information Network (GAIN) Report Number: NL5028), USDA Foreign Agricultural Service (The Hauge post). 7/15/2015., 2015.

[24] H. Persson, P. Blomqvist, Z. Yan, Brand och brandsläckning i siloanläggningar - en experimentell studie. SP Rapport 2006:47 (In Swedish) [Fire and extinguishment in silos - an experimental study], Sveriges Provnings- och Forskningsinstitut (SP), Borås, Sweden, 2006. http://rib.msb.se/Filer/pdf/23961.pdf (Retrieved 26 March 2016).

[25] P. Modin, Brand i Lantmännens silo i Kristinehamn. 29/9 - 4/10 2007 (in Swedish) [Fire in Lantmännen's silo, Kristinehamn, Sep 29 - Oct 4, 2007], Kristinehamn, Sweden, n.d. http://rib.msb.se/Filer/pdf/26249.pdf (Retrieved 26 March 2016).

[26] H. Persson, Silo Fires Require Specific Response Tactics, Biomass Mag. (2011).

http://biomassmagazine.com/articles/5910/silofiresrequirespecificresp onsetactics/ (Retrieved 20 Dec 2015).

[27] H. Persson, Responding Safely to Silo Fires, Can. Biomass. (2011). http://www.canadianbiomassmagazine.ca/news/respondingsafelytosil ofires3013 (retrieved 20 Dec 2015).

[28] J. Koppejan, A. Lönnermark, H. Persson, I. Larsson, P. Blomqvist, M. Arshadi, E. Valencia-Reyes, S. Melin, P. Howes, P. Wheeler, Health and safety aspects of solid biomass storage, transportation and feeding, IEA Bioenergy (NL Agency), Enschede, The Netherlands, 2013. 
[29] F.H. Hedlund, J. Astad, J. Nichols, Inherent hazards, poor reporting and limited learning in the solid biomass energy sector: A case study of a wheel loader igniting wood dust, leading to fatal explosion at wood pellet manufacturer, Biomass and Bioenergy. 66 (2014) 450459. doi:http://dx.doi.org/10.1016/j.biombioe.2014.03.039.

[30] F.H. Hedlund, Ø.J. Hilduberg, Fatal Accidents During Marine Transport of Wood Pellets Due to Off-gassing - Experiences from Denmark, in: J.S. Tumuluru (Ed.), Biomass Vol. Estim. Valorization Energy, InTech, Rijeka, Croatia, 2017: pp. 73-97. doi:http://dx.doi.org/10.5772/66334.

[31] F.H. Hedlund, J. Astad, Solid Biomass Climate Change Interventions Examined in a Context of Inherent Safety, Media Shifting, and Emerging Risks, Hum. Ecol. Risk Assess. 21 (2015) 1410-1427. doi:10.1080/10807039.2014.957954.

[32] B.K. Sovacool, R. Andersen, S. Sorensen, K. Sorensen, V. Tienda, A. Vainorius, O.M. Schirach, F. Bjørn-Thygesen, Balancing safety with sustainability: assessing the risk of accidents for modern low-carbon energy systems, J. Clean. Prod. 112 (2016) 3952-3965.

[33] V.C. Moreno, V. Cozzani, Major accident hazard in bioenergy production, J. Loss Prev. Process Ind. 35 (2015) 135-144.

[34] S.S. Rivera, R.D.C. Olivares, P.A. Baziuk, J.E.N. Mc Leod, Assessment of Biofuel Accident Risk: A Preliminary Study, in: Proc. World Congr. Eng., 2015.

[35] N.A. Ashford, Industrial safety: the neglected issue in industrial ecology, J. Clean. Prod. 5 (1997) 115-121. doi:https://dx.doi.org/10.1016/S0959-6526(97)00024-3. 